\title{
Teoria das representações sociais e história: um diálogo necessário
}

\author{
João Gilberto da Silva Carvalho \\ Angela Arruda
}

Universidade Federal do Rio de Janeiro, Rio de Janeiro-RJ, Brasil

\begin{abstract}
Resumo: O artigo apresenta nossos esforços em articular dois campos do saber humano, psicologia social e história, como parte de uma pesquisa que envolve a compreensão do impacto psicossocial à presença de chineses no Brasil do século XIX. A partir da teoria das representações sociais, o objetivo é contribuir para uma psicologia histórica que seja capaz de integrar temas comuns às ciências humanas, tais como alteridade, imaginário e modernidade. A flexibilidade da corrente inaugurada por Moscovici permite a análise não apenas do "estranhamento" como da "naturalização" dos fatos que se tornam históricos. Assim, o diálogo entre as referidas disciplinas se mostrou promissor em nosso trabalho e mais uma possibilidade de alargamento de campo à teoria das representações sociais.
\end{abstract}

Palavras-chave: Psicologia social. Representação social. Interdisciplinaridade.

\section{The theory of social representations and history: a necessary dialogue}

Abstract: This article presents our efforts to connect two fields of human knowledge, social psychology and history, as part of a study aimed to understand the psychosocial impact of the Chinese in Brazil in the $19^{\text {th }}$ century. Based on the theory of social representations, it aims to contribute to a historical psychology capable of integrating common themes in human sciences like otherness, imaginary and modernity. The flexibility of Moscovici's theory allows analyzing not only "strangeness" but also "naturalization" of facts that become historical. The dialogue between history and social psychology is promising in our work and is another possibility of enlarging the field of social representations.

Keywords: Social psychology. Social representation. Interdisciplinarity.

\section{La teoría de las representaciones sociales y la historia: un diálogo necesario}

Resumen: Este artículo presenta nuestros esfuerzos hacia una articulación entre dos campos del conocimiento humano, psicología social e historia, la cual hace parte de una investigación relativa al impacto psicosocial provocado por la presencia de chinos en Brasil en el siglo XIX. A partir de la teoría de las representaciones sociales, su objetivo es contribuir para una psicología histórica capaz de integrar temas comunes a las ciencias humanas, tales como alteridad, imaginario y modernidad. La flexibilidad de la corriente inaugurada por Moscovici permite el análisis no solamente del "extrañamiento" sino también de la "naturalización" de los hechos que se vuelven históricos. De esa manera, el diálogo entre aquellas disciplinas se ha mostrado importante en nuestro trabajo y trae más una posibilidad de ampliación al campo de la teoría de las representaciones sociales.

Palabras clave: Psicología social. Representación social. Interdisciplinaridad. 
As reflexões a seguir constituem esforços no sentido de promover um diálogo entre a teoria das representações sociais e a história. Estudos em representações sociais podem ser enriquecidos com a dimensão histórica, não apenas porque toda representação se refere a um tempo-espaço, mas porque a própria historicidade está na base da transformação social - objeto por excelência dos trabalhos realizados pela corrente inaugurada por Moscovici (1978) e que tem recebido significativos acréscimos, abarcando novas temáticas das ciências humanas ao longo dos anos (Jodelet, 2001; Wagner, 1998). O diálogo com a história está presente de forma sistemática na obra de Moscovici, embora suas influências sejam mais explícitas em relação à sociologia. Mas nossa pesquisa não significa apenas a incorporação da dimensão histórica às representações sociais, implica, outrossim, em considerar um fato histórico na sua relação com representações sociais, tal como será visto adiante.

Ao eleger as representações sociais para nortear nossa pesquisa, sentimos a necessidade de buscar aporte em outras áreas, especialmente na história, surgindo, como era esperado, dificuldades e incompreensões. História e psicologia são áreas do conhecimento humano que não costumam dialogar com freqüência. No passado de uma psicologia centrada no indivíduo e de uma história que se contentava com fatos, tal diálogo era realmente impossível. Para que fique mais claro, é necessário mencionar aqui o objetivo da pesquisa que deu origem às reflexões do presente artigo: análise das representações sociais provocadas pela imigração chinesa no Brasil do século XIX (segundo quartel), no contexto de formação da identidade nacional. Realizamos, portanto, um estudo do impacto psicossocial causado pela presença chinesa no Brasil entre 1850 e o final do Segundo Império. O problema central foi entender como o coolie é inserido simbolicamente numa dinâmica de imigração que se choca com o processo de formação da nação. Paradoxalmente, de um trabalhador chinês que não precisou ser visto para ser conhecido, pois já existia no imaginário construído ao longo da modernidade ocidental. Não foi fácil enquadrar nossa pesquisa num "território" definido do mundo acadêmico, sobretudo na psicologia, segmento da ciên- cia que também enfrenta problemas de localização: ciência social ou médica? A afirmação de que se trata de uma pesquisa em psicologia social resolve em parte a contenda, pois não bastassem os problemas epistemológicos da disciplina-mãe, a psicologia social tem suas correntes e conflitos internos em que se digladiam as formas sociológicas e individualizantes de abordagem (Farr, 2004; Spink \& Menegon, 2000; Vala, 1993). Mas a escolha da psicologia, no caso a psicologia social, teve razão de ser. Afinal, a perspectiva não era a de lidar tão somente com fatos e sim relacioná-los a fenômenos de natureza complexa, tais como imaginário, modernidade e alteridade. $\mathrm{Ou}$ seja, tornava-se necessário utilizar uma teoria que abarcasse os processos de construção de subjetividades - campo por excelência da psicologia social. No caso, um ramo da psicologia em sua forma sociológica que se desvencilhou do individualismo hegemônico da corrente norte-americana.

Fala-se correntemente em interdisciplinaridade, muito se comenta sobre o rompimento de paradigmas, do holístico e complexo, mas nossas práticas e concepções muitas vezes derivam de rótulos ou, como veremos adiante com maior propriedade, de representações sociais. Historicamente a ciência se descolou da filosofia e criou ramos que correspondem a objetos distintos e muitas vezes irreconciliáveis, pelo menos na forma em que são apresentados. A especialização contribuiu para o avanço das pesquisas em muitas áreas, é inegável, mas criou distorções que são expressas nas críticas feitas ao cientificismo, que pode ser traduzido historicamente numa perspectiva monista. O paradigma de uma ciência única sofre pesadas críticas na atualidade e as pesquisas se abrem para novas alternativas e abordagens (Spink \& Menegon, 2000).

Em ciências sociais, fronteiras muitas vezes arbitrárias separam a história, a sociologia, a antropologia e a psicologia, para ficarmos apenas no campo de nosso interesse (Farr, 2004). O diálogo que seria extremamente profícuo torna-se difícil em função do repertório teórico que as corporifica. Não são apenas diferenças conceituais, como também humanas em termos de interesses e perfis profissionais construídos ao longo de décadas. Paradoxalmente, a alteridade está consolidada entre estudiosos que se pro- 
põem a abordar o fenômeno da alteridade, fazendo-se presente o conceito de dupla hermenêutica, abordado por Domingues (2003): os intelectuais interpretam o mundo, mas são parte efetiva-afetiva dele e como tal, objetos historicamente construídos.

Nossa pesquisa envolve temas que transitam entre as ciências do homem, na medida em que identidade, memória e representações não são patrimônios exclusivos de qualquer uma delas, o que nos deixou à vontade para fazer escolhas, ao mesmo tempo em que nossa responsabilidade tornou-se maior. Afinal, qual a compatibilidade, por exemplo, entre o imaginário de Castoriadis (1982) e a teoria das representações sociais de Moscovici (2003)? Como utilizar o conceito de memória (Le Goff, 1924/2003) numa perspectiva sócio-genética (Wagner, 1998)? E por fim, ao assumir a teoria das representações sociais como instrumento de análise, até que ponto buscar aporte em outras teorias (ou domínios)? Realizar uma pesquisa é tarefa complexa e não é à toa que os manuais de metodologia têm seu altar cativo nas livrarias. E não se trata apenas de uma questão de modelo, mas de procedimentos efetivos. Quais são os critérios em que se delineia o corpus de uma pesquisa? No caso, especificamente, significa ter consciência da seleção de grupos e instituições que sejam representativos do fenômeno pesquisado, sua relação com os processos identitários da época em tensão com as representações sociais sobre os chineses.

É agora evidente nossa escolha na psicologia: a teoria das representações sociais. Trata-se de uma escola, no sentido definido por Freitas (1998), que tem realizado pesquisas em diversas áreas da atividade humana, com predomínio em educação e saúde, como evidenciado na V Jornada Internacional e III Conferência Brasileira sobre Representações Sociais, último congresso internacional da área, realizado no Brasil (Anais, 2007). As pesquisas em história neste campo ainda são tímidas, como podemos constatar no referido evento, não apenas como participantes, mas pela leitura do programa oficial. Por outro lado, nossa participação em tal congresso convenceu-nos da inexistência de incompatibilidade entre as representações sociais e a história, mas ao contrário, de que se trata de um diálogo necessário, daí as presentes reflexões.
Há menções a temporalidade em obras de psicólogos sociais, o sentido histórico de um fenômeno ou mesmo à própria história da psicologia. Não é a esse tipo de "história" que nos referimos. A partir de definições apressadas, que situam a história no passado e as representações sociais no presente, a realização de uma pesquisa como a nossa seria praticamente inviável. Então, com a devida prudência, mas enfaticamente, adotaremos duas premissas básicas: (a) não existe representação social fora da história; (b) considerando-a uma forma narrativa, não existe história que prescinda de representações sociais. Tal diálogo é possível entre uma perspectiva processual de representações sociais e uma história desprovida de determinismos ou "motores". Ou seja, o fio condutor para um diálogo deve ser procurado não no nível imediato das pesquisas, mas do paradigma (Kuhn, 1962/2006) que é subjacente tanto às representações sociais enquanto teoria, como à história cultural aqui destacada, seguindo as recomendações de Elias (1939/1993) no sentido de uma psicologia histórica, isto é, buscar a relação entre processos sociais e mentais.

\section{Representações sociais: definição}

A tríade do conhecimento é composta em termos tradicionais por sujeito, objeto e o produto desta relação (Schaff, 1971/1987). A natureza social da vida humana implica num relacionamento constante entre tais componentes. Assim, por uma questão de coerência teórica, é de fundamental importância adicionarmos o plural e desta forma sairmos de uma concepção solipsista e transcendental do conhecimento. Uma prudência que, entretanto, não elimina problemas decorrentes do dualismo filosófico, alimento de discussões acaloradas há séculos.

Inicialmente, a questão da primazia sobre o processo. A representação é subjetiva ou objetiva? Isto é, o conhecimento deriva "simplesmente" da vontade de sujeitos ou está ligado à natureza dos objetos? E outra não menos importante: sobre a possibilidade de se definir ou obter um conhecimento verdadeiro, isto é, que expresse inteiramente o objeto. Se, parafraseando os sofistas, o homem é a medida do conhecimento, então não há verdades absolutas. Mas talvez apenas os sentidos humanos sejam falhos, 
num mundo governado por leis inexoráveis. A filosofia grega lutou para se afastar da opinião, criando o mundo das idéias ou as essências dialeticamente construídas. Sob diferentes roupagens a controvérsia estimulou debates ao longo da história. E o mundo das idéias platônicas se transformou nas verdades claras e distintas de Descartes. Mais tarde, já no século XIX, a ciência positivista tornou-se a porta-voz dos ideais da objetividade e assim, mesmo em ciências humanas, só deveria ser estudado o que pudesse ser visto e mensurado. Mas a sombra do ceticismo sempre esteve presente, de Sexto Empírico ao pós-modernismo, passando por Hume, o historicismo de Dilthey e mesmo a fenomenologia. Evidentemente, há diferenças epistemológicas entre as escolas de pensamento nada desprezíveis - mas é possível visualizar um pêndulo que oscila entre a subjetividade e a objetividade.

Em termos práticos e sintéticos, foram criados dois paradigmas apoiados em visões de mundo supostamente incompatíveis e que norteiam pesquisas e abordagens excludentes. O debate que opõe as chamadas pesquisas qualitativa e quantitativa é a roupagem que adquire a questão na década 1980, como nos informa Alves-Mazotti (1996, p. 16), em suas considerações acerca dos paradigmas educacionais: "os rótulos quantidade versus qualidade tornaram-se pregnantes, cada um deles, aglutinando em torno de si características referentes a outras dicotomias igualmente simplificadoras como descritivo versus interpretativo, objetivo versus subjetivo, entre outras". $\mathrm{Na}$ atualidade este debate não provoca tanto alvoroço, embora as perspectivas ainda continuem a produzir pesquisas e livros.

Há certas idéias que possuem "linhagem" e no Ocidente a filosofia grega é a matriz de muitas delas, tais como razão, justiça, verdade, entre outras, que expressam themata. Ou seja, "modos de pensamento que a vida cotidiana sustenta e que são historicamente mantidos por mais ou menos longos períodos" (Moscovici, 2003, p. 218). Tão enraizados que praticamente imperceptíveis, garantem a permanência de estruturas até em contextos caracterizados pelo extremo dinamismo, como nas sociedades modernas. Mesmo as sofisticadas elaborações da filosofia ou da ciência indicam um conjunto de relações sociais às quais estão ligadas e lhes garante sentido.
O termo representação é polissêmico, possui longa tradição e uso. Em geral, indica um "algo" que se insere entre um sujeito e um objeto; e traduz a dualidade básica da existência humana. São imagens, palavras, símbolos, ações e expressões, enfim, decorrentes das atividades e interações humanas - o ser no mundo que se faz no tempo. Assim, utilizada como expressão vaga por diferentes correntes de pensamento, a representação em seus múltiplos usos torna a coexistência possível (e mesmo impossível), de acordo com o contexto histórico. Ainda que, como nos advertiu Jovchelovitch (2004), não se possa ignorar a predisposição biológica para a atividade cognitiva, a representação só tem sentido na relação com o outro. Chartier expõe-nos a dupla função da representação: "a representação como dando a ver uma coisa ausente, o que supõe uma distinção radical entre aquilo que representa e aquilo que é representado; por outro, a representação como exibição de uma presença, como apresentação pública de algo ou alguém" (Chartier, 1990, p. 20). Um quadro ou um ator no palco tanto evoca e substitui a realidade que representa, como também pode distorcê-la .

A definição não é nova, mas a teoria das representações sociais não é uma roupagem moderna para o nominalismo ou uma modalidade de negação pós-moderna da realidade. Apresenta-se como tendência na psicologia social a partir dos estudos de Moscovici (1978) sobre a forma como a psicanálise foi inserida e apropriada historicamente pela sociedade francesa. Mas não foi fácil à teoria romper as barreiras e penetrar no mundo anglo-saxão (Leme, 1995). A corrente das representações sociais se opunha ao individualismo da tradição behaviorista e da cognição social, uma reação ao positivismo. Ainda que tenha em Durkheim seu precursor imediato no uso do conceito, Moscovici (2001) não deixa dúvidas quanto ao seu débito e afirma:

O verdadeiro inventor do conceito é Durkheim, na medida em que fixa os contornos e lhe reconhece o direito de explicar os fenômenos mais variados na sociedade. Ele o define por (...) uma ampla classe de formas mentais (ciências, religiões, mitos, espaço, tempo), de opiniões e saberes sem distinção (p. 47). 
O conceito de representação coletiva de Durkheim procura dar conta de fenômenos que caracterizam e mantêm a vida em sociedade. Mas ao priorizar os processos de manutenção das instituições sua sociologia se mostra pouco preocupada em explicar a mudança. Evidentemente seu projeto era consolidar a sociologia como uma ciência nos moldes estabelecidos pela corrente positivista do século XIX. Ao eleger as representações sociais como seu objeto por excelência, Moscovici (2001) desenvolve uma teoria que prioriza a mudança. Como por exemplo: "o que acontece quando os atores sociais são levados a desenvolver práticas sociais em contradição com seu sistema de representação" (Abric, 1998, p. 35). Neste caso, quando a solidariedade é perturbada, ao serem abalados os alicerces de sua comunhão, são mobilizados esforços promotores de um novo equilíbrio: "quando a novidade é incontornável, à ação de evitála segue-se um trabalho de ancoragem com o objetivo de torná-la familiar e transformá-la para integrá-la no pensamento preexistente" (Jodelet, 2001, p. 35).

$\mathrm{Na}$ vida social equilíbrio e desequilíbrio caracterizam processos dinâmicos nos quais as representações são sistematicamente atualizadas, o que não significa dizer que sejam desprovidas de estabilidade e mudem ao bel prazer das vontades individuais. Ao contrário, enquanto atividade social produtora de significados e sentidos revela-se independente e provida de uma lógica inerente ao contexto social em que é produzida (Wagner, 1998). Portanto, mais que um símbolo descolado do real ou que lhe dá simplesmente substrato, as representações são ambientes de pensamento, sua força reside nos processos de socialização que as tornam uma forma independente de conhecimento e modificação da realidade. Nas sociedades em que são criadas, a partir de um imaginário que se perde no tempo, as representações circulam e se chocam em constante atrito com a própria dinâmica do dia-a-dia.

A estabilidade das representações é garantida por seu aspecto compartilhado, consensual e nesse sentido pouco importa sua base real. Não há sentido ou mesmo utilidade em afirmar a existência da realidade por si mesma - um mundo objetivo tal como pugnam os "realistas" de diferentes matizes, se ela só é conhecida por suas representações.
As representações se tornam tangíveis para o grupo considerado já que seus membros acreditam em sua existência. A representação não é apenas a expressão simbólica da realidade como sua via de acesso, ou seja, deriva da atividade do homem e a direciona, é simultaneamente produto e processo. Refere-se à transformação do não-famililar em familiar, quando o novo é incorporado a categorias preexistentes e se torna senso comum. Na perspectiva desta teoria e das pesquisas por ela motivadas, significa apreender a ancoragem e a objetivação em que são geradas e desenvolvidas. $\mathrm{O}$ foco é o senso comum, a maneira como as pessoas pensam ao se apropriarem de forma inventiva do mundo (Ribeiro, Oliveira, Coutinho, \& Araújo, 2007). Neste sentido a teoria das representações sociais rompe com as tradições que desdenham o conhecimento do homem comum, seja por considerá-lo falsa consciência (ideologia) ou pura ignorância.

Alicerce das identidades e, conseqüentemente, o ponto de partida para as diferenças, as "representações estão presentes tanto 'no mundo' como 'na mente", (Farr, 1994, p. 46), portanto, elementos indissociáveis do processo cognitivo de estar no mundo, pois realizam a mediação "entre o sujeito e o mundo que ele ao mesmo tempo descobre e constrói" (Jovchelovicth, 1994, p. 78). Em termos de uma psicologia social, significa referir-se a formas de pensamentos produzidos na esfera pública e que se consolidam nas comunicações do grupo. As representações, afirma Jodelet (2001, p. 17), "são trazidas pelas palavras e veiculadas em mensagens", ou seja, orientam as ações compartilhadas (comunicação) e as condutas individuais.

A partir dos estudos de Moscovici, desponta uma teoria que se discute sistematicamente, sendo a preocupação epistemológica uma constante em trabalhos de representações sociais. As pesquisas abrangem diversos segmentos da atividade científica, sem respeitar as fronteiras tradicionais cunhadas pela especialização acadêmica, tais como educação, saúde, comunicação e ciência, memória e cultura (Arruda, 2005). Portanto, impulsionada pela psicologia social, a teoria ganhou fôlego e ampliou não apenas suas aplicações, como também é possível observar algumas tendências divergentes. Como não poderia 
deixar de ser, na esteira do sucesso surgiram críticas, notadamente internas, no seio da psicologia social. Em geral, como observa Leme (1995), referiam-se à ausência de definição do próprio conceito de representação social, a autora cita trechos de Moscovici em que a ausência de precisão conceitual é admitida. Ao contrário do que supõe Leme, acreditamos que a dimensão alcançada pela teoria exige a busca de autores que se preocuparam com a sistematização do conceito, notadamente Jodelet (2001).

\section{História e representação social}

$\mathrm{O}$ trabalho de pesquisa a que nos dedicamos se situa entre domínios consagrados das ciências humanas: a história e a psicologia social. A questão central do estudo é compreender as representações sociais sobre chineses no segundo quartel do século XIX, no momento em que segmentos da sociedade brasileira discutiam: (a) a identidade nacional - quem pode ser considerado brasileiro; (b) as perspectivas do mercado de trabalho pós-escravidão.

Identidade, memória e representações são temas comuns a obras de historiadores e psicólogos, poderiam ser incluídos neste rol sociólogos e antropólogos. A pergunta é inevitável: a teoria das representações tem como aplicação somente questões do tempo presente? E caso seja, não haverá, então, incompatibilidade entre a teoria e a história? Não as representações em geral, mas tal como formuladas por Moscovici (1978, 2001, 2003) e Jodelet (2001, 2005). Ou, ao contrário, é possível utilizá-las enquanto teoria capaz de dar suporte a trabalhos de cunho historiográfico, como o nosso, caracterizado por sua natureza temporal? No tópico anterior, a intenção foi caracterizar as representações sociais epistemologicamente. Agora, o mesmo se faz necessário, afinal, de que corrente historiográfica estamos falando?

Ultrapassada a fase de hegemonia positivista e sua pretensão de contar os fatos como realmente ocorreram, a historiografia "explodiu" em correntes distintas e mesmo antagônicas, como nos relata o historiador britânico Jenkins (2001, pp. 36-37):

Quem você gostaria de seguir? Há Hegel, Marx, Dilthey, Weber, Popper, Hempbel, Aron, Collingwood, Dray, Oakeshott, Danto, Galie (...) Ou você prefere os empiricistas modernos, as feministas, a escola dos Annales, os neomarxistas, os neoestilistas, os econometristas, os estruturalistas ou mesmo o próprio Marwick?

Provavelmente em nenhuma área o combate - esse bordão às pretensões positivistas - é tão acirrado, principalmente se considerarmos que as próprias correntes se ramificam em outras tantas. Muito já se discutiu quanto às possibilidades de uma ciência da história, o que não a impediu de continuar produzindo novos e bons frutos, como a história cultural e a microhistória, por exemplo. O boom editorial se traduziu em filmes, livros, revistas e até a ressurreição das biografias e obras de memorialistas. Existe, portanto, a história dos especialistas, divididos por suas teorias e concepções filosóficas, a história do homem comum, que a vive e representa ao lado daquela que é ensinada nas escolas em livros didáticos e publicações. A pergunta do filho de Bloch "para que serve a história" (Bloch, 1976, p. 11) foi transformada por Jenkins (2001) em para quem serve a história. Para usar um jargão comum entre os historiadores, o ofício do historiador continua em debate, mas a história dos historiadores deve se contrapor ao senso comum, pelo menos é o que nos recomenda Le Goff em obra clássica: "É desejável que a informação histórica, fornecida pelos historiadores de ofício, vulgarizada pela escola (ou pelo menos deveria sêlo) e pela mass media, corrija esta história tradicional falseada" (Le Goff, 1924/2003, p. 29). Esse modelo não se coaduna certamente com a teoria das representações sociais.

A história enquanto saber humano pode ser considerado essencial às sociedades, haja vista sua ancestralidade e existência em distintas sociedades. Neste sentido, é uma produção tipicamente humana, o que levaria no século XVIII o filósofo Vico a afirmar que, ao contrário da natureza, somente a história poderia ser objeto pleno do conhecimento, afinal "só se conhece o que se criou" (Reis, 2005, p. 220). Decididamente a história se afasta (ou tenta) da metafísica (filosofia da história) e da literatura para se fazer ciência. Evidentemente o inconveniente de uma visão panorâmica é a generalidade. O positivismo se tornou majoritário no século XIX e meados do XX, mas não sem ferrenhas oposições. 
Ao definir o objeto por excelência da história, Braudel (1969/1992) distingue a longa e a curta duração. O tempo longo seria o campo do historiador, e o curto objeto das demais ciências do homem. Já foi o tempo em que tal distinção era de alguma forma respeitada. Da pretensão de uma história total a uma história em migalhas (Reis, 2005, p. 73), as concepções foram acompanhando as mudanças da sociedade e as certezas de um tempo iluminista, governado pela razão, foram substituídas pelas incertezas da pós-modernidade.

A pluralidade de correntes aproximou a história de abordagens típicas de outras ciências do homem e assim o conceito de fonte foi ampliado. Num primeiro instante, o movimento de renovação na França criou a chamada escola das mentalidades. E aqui temos nossa primeira aproximação com as representações sociais. Para Moscovici (2001, p. 45), os estudos sobre mentalidades fizeram com que o conceito de representação coletiva não fosse relegado ao esquecimento. Entretanto, se as mentalidades representaram um novo eixo temático, abarcando elementos do imaginário e da cultura, em termos metodológicos os procedimentos continuaram os mesmos que contribuíram para popularizar a história social. As críticas pesadas às séries estatísticas e aos modelos generalizantes acabaram por reduzir a história, repetindo a expressão de Dosse, a migalhas, ou seja, fracionada em correntes cada vez mais díspares, tanto que a relação de Jenkins (2001), acima, certamente está defasada.

De um modo geral, desde Dilthey são feitas por historiadores incursões no campo da psicologia e vice-versa. Mas nessa busca por novos horizontes a utilização do conceito de representação por historiadores é central na obra de Chartier (1990) e sua história cultural. Além de usar o conceito de representação destacadamente, Chartier (1990) faz menções a Durkheim e a Lévy-Bruhl, autores que influenciaram Moscovici e a relação daqueles com a escola dos Annales.

A importância dos ensaios de Chartier está em exemplificar e discutir as mudanças na abordagem, como ele diz, "da história social da cultura para a história cultural da sociedade". Isto é, os ensaios sugerem que o que os historiadores anteriores, pertencentes ou não à tradição dos Annales, geralmente aceitavam como estruturas objetivas, devem ser vistas como culturalmente constituídas ou "construídas", "a sociedade em si mesma é uma representação coletiva” (Burke, 1997, p. 98). Com efeito, Chartier (1990) critica a concepção de um social que existe por si mesmo e gera representações entendidas como meros reflexos ou epifenômenos. Tal concepção não se expressa apenas na percepção ortodoxa que reivindica a primazia da infraestrutura sobre a superestrutura. Senão vejamos a definição de imaginário de Pesavento (1995, p. 15):

O imaginário faz parte de um campo de representação e, como expressão do pensamento, se manifesta por imagens e discursos que pretendem dar uma definição de realidade (...) As representações objetais, expressas em coisas ou atos, são produto de estratégias de interesse e manipulação.

Aqui a representação aparece basicamente em sua função de estrutura estruturada (Spink, 1995). Entretanto, como estrutura estruturante, as representações (sociais) oferecem matrizes sobre as quais o pensamento trabalha. Ao serem propostas como interface entre sujeitos e objetos, as representações sociais assumem o estatuto de ambiente de pensamento. Mas voltando a Chartier (1990), percebe-se que sua aproximação à teoria das representações sociais é evidenciada pela aceitação da primazia do coletivo durkheimiano. Ao comentar as mentalidades, afirma:

A relação entre a consciência e o pensamento é colocada de uma forma nova, próxima da dos sociólogos da tradição durkheimiana, pondo em relevo os esquemas ou os conteúdos do pensamento que, embora enunciados sobre o modo do individual, são de facto os condicionamentos não conscientes e interiorizados que fazem com que um grupo ou uma sociedade partilhe, sem que seja necessário explicitá-los, um sistema de representações e um sistema de valores (Chartier, 1990, p. 41).

Em Chartier, "seu conceito de representação visa ao mesmo objetivo central de Bourdieu: ultrapassar 
nas ciências sociais - e, portanto, na história -, a oposição entre "física social' e 'fenomenologia social"" (Cardoso \& Malerba, 2000, p. 16). Para o historiador francês a história é uma narrativa e na atualidade se preocupa menos com as estruturas que com as redes onde se desenvolvem as estratégias indispensáveis à vida social. Uma narrativa, mas não uma forma de literatura, pois a história se remete a fontes e ligações intersubjetivas, pode ser criativa, mas não inventada ao bel prazer do historiador. Chartier (1990, 1994) não faz qualquer menção ao trabalho de representações desenvolvidos na psicologia social, suas influências explícitas são principalmente Elias e Bourdieu, mas é possível também detectar com facilidade seu diálogo com Certeau, Veyne, entre outros, nada ortodoxos em termos epistemológicos. Não apenas Chartier e seu conceito de apropriação (Burke, 1997, p. 99), como demais autores da história cultural aqueles que assumem uma dimensão antropológica em suas análises na busca de uma "poética da história" (Diehl, 2002, p. 123) - oferecem, a nosso juízo, suporte para trabalhos em que a dimensão histórica das representações sociais é requisitada.

\section{Pontos de contato}

Optamos pela teoria das representações sociais por considerá-la um instrumento consistente de pesquisa que circula com desembaraço entre os diferentes segmentos da ciência, o que constitui no segredo de seu sucesso, como destaca Leme (1995, p. 56) ao afirmar que a preocupação de Moscovici foi abrir um campo de pesquisa flexível e não um paradigma magro e solitário.

Apesar de utilizar temas caros aos trabalhos de historiadores, como memória e identidade, nem sempre a dimensão histórica das representações sociais tem recebido o devido destaque ou aparece apenas em referências ligeiras. $\mathrm{O}$ contexto social é realçado e não poderia ser de outra forma, pois a representação é sempre integrante de um todo mais amplo com o qual se articula. O trabalho que desenvolvemos segue provocando estranheza (ancoragens?) em minhas conversas e solicitações de ajuda a historiadores e psicólogos. Os primeiros, ao ouvirem falar em representação se apressam em endossar as críticas a Chartier, afirmando que seu trabalho é inconsistente.
E além das supostas inconsistências teóricas de sua história cultural (Cardoso \& Malerba, 2000; Pesavento, 1995), ele seria um pós-moderno! Com relação às representações, o historiador Flamarion afirma:

Em minha opinião, a noção de representação social pode ser útil, operacionalmente, em muitos de seus usos e conceituações (...) Pessoalmente, pertenço ao grupo daqueles que acham pelo contrário, que, quando se tenta absolutizar essa noção - quando ela é tomada literalmente -, ela entra "em conflito com o fato óbvio de que não criamos mundos, mas sim que estamos em um": um mundo físico que indubitavelmente não criamos e que nos precede (Cardoso \& Malerba, 2000, p. 10).

E conclui: "Os psicólogos sociais, felizmente para eles, não parecem sentir a tentação de tudo reduzir às representações coletivas: estas constituem um de seus domínios de trabalho" (Cardoso \& Malerba, 2000, p. 23). Mas não se trata apenas de uma questão de domínio ou reserva de mercado. Heller (1970/2000), por exemplo, relaciona cotidiano e história através de conceitos como imitação e motivação. Assim, é preciso também conhecer os referenciais dos autores que utilizamos, como no caso da historiadora marxista. As correntes possuem especificidades, é preciso admitir, e as conexões não podem ser estabelecidas de forma arbitrária, embora tal prudência não possa significar um legítimo impedimento. Seja como for, o tempo das ortodoxias tem cedido vez às experimentações, rompimentos de barreiras, o que talvez se configure num movimento tão inexorável quanto estimulante (Lincoln \& Guba, 2003, p. 170). As conexões foram perdidas somente no emaranhado de conceitos produzidos ao longo do tempo, mas os contatos são perceptíveis, por exemplo:

Caracterizar o Oriente como estranho e incorporá-lo esquematicamente num palco teatral cujo público, gerente e atores estão voltados para a Europa, e apenas para a Europa. Por isso a vacilação entre o familiar e o estranho; Maomé é sempre o impostor 
(familiar, porque ele pretende ser como o Jesus que conhecemos) e sempre o oriental (estranho, porque, embora seja em alguns aspectos "semelhantes" a Jesus, afinal ele não é como Jesus) (Said, 1978/2007, p. 113).

O autor ao caracterizar o orientalismo praticamente esboça os processos de ancoragem e objetivação das representações sociais. Seu trabalho é um esforço no sentido de demonstrar como um imaginário "oriental” foi construído e consolidado ao longo dos séculos e continua a permear as ações e políticas não só das potências quanto dos intelectuais que lidam com os povos do leste. Said (1978/2007) faz referências constantes ao discurso, cita Foucault com frequiência, teoriza sobre um processo de alteridade, portanto.

As representações sociais expressam a tensão constante do cotidiano e suas demandas históricas. Muitas vezes o conteúdo das representações parece desafiar o tempo (themata) e não há como prever ou antecipar o seu fim; a história não tem uma direção linear como supunham os evolucionistas do século XIX. Do ponto de vista das representações sociais, o novo, estranhado, torna-se familiar e dotado de um sentido, amálgama entre a novidade e o já conhecido. A representação então materializada no senso comum adquire "vida" própria como produto da atividade social (Moscovici, 2003). Há uma lógica interna, um sistema de categorizações e hierarquias que as tornam um sistema de pensamento, não do indivíduo, mas inerentes ao todo do qual faz parte. Portanto, as representações estão na base do senso comum, nos processos de comunicação e interação cotidianos, quando então emulam os quadros de referência para a ação (Jodelet, 2001). Tal é a essência da mudança social e dos processos constituintes da identidade e da alteridade; que no repertório conceitual desta corrente são chamados de ancoragem e objetivação. Sendo sociais, as representações são inevitavelmente históricas (Rouquette, 1994), produzidas em contextos que resultam de processos sucessivos e em direções possíveis, seu caráter simultaneamente estruturante e estruturado é um embate entre o passado e o presente. E assim, afirma Moscovici (2003, p. 38), “o passado é mais real que o presente".
Após tais considerações podemos afirmar que o diálogo entre a história e a teoria das representações sociais não é só possível como fundamental. Principalmente naquelas fronteiras em que a proximidade é mais visível, nas reflexões que tratem de memória, identidade e alteridade. O contexto para articulações é favorável, como se depreende das inquietações do historiador Diehl (2002, p. 123):

Pois bem, a pergunta instigante é a seguinte: por que a memória coletiva e individual assume atualmente um papel central na historiografia? Penso ser possível mapear argumentos centrais, entre outros. O primeiro argumento vincula-se à crise da história como ciência, enquanto o segundo relaciona-se com as formas de representação histórica, ou melhor, a narração histórica (a poética da história).

Durante a realização da V Jornada Internacional e III Conferência Brasileira sobre Representações Sociais (Anais, 2007), diariamente, conforme se observa na programação oficial do evento, foram realizados grupos temáticos em "memória, história, e cultura/política". Na oportunidade apresentamos nossa pesquisa ao grupo com a premissa de que os processos de ancoragem e objetivação são “cristalinos" numa perspectiva histórica. Ou seja, a novidade (a imigração chinesa), a reação ao novo (debates sobre identidade, mercado de trabalho) e sua acomodação ao sistema preexistente (teorias raciais, exclusão do trabalhador chinês), constam em documentos, matérias de imprensa, discursos, entre outras práticas de natureza social que materializaram o fenômeno - são indícios, para usar um termo caro à micro-história (Ginzburg, 1986/2007). Assim, procuramos demonstrar a possibilidade de transformar um fato histórico num objeto de estudo pela teoria das representações sociais. A estimulação para a busca de novas perspectivas em representações sociais é feita pelo próprio criador da teoria, que declara em bom tom não ser o guardião de uma pureza original (Moscovici, 2007, p. 12).

A realização da pesquisa em todos os seus objetivos tem demandado uma "caixa de ferramentas", que além da teoria das representações sociais 
inclui a obra de diferentes segmentos das ciências humanas. Sob a égide da alteridade, a imigração causou mais bate-boca e mal estar que entrada de trabalhadores no Brasil. E os que vieram simplesmente "desapareceram"!

\section{Considerações finais}

Ao longo do presente artigo discutimos a relação entre representações sociais e história como parte das inquietações metodológicas de uma pesquisa situada entre as duas áreas. Por destacar as representações sociais das coletivas, Moscovici elegeu como objeto de seus estudos os contextos caracterizados pela mudança. Evidentemente sociedades primitivas ou mesmo sociedades ocidentais pré-modernas não estão incluídas neste rol. A nosso juízo tal perspectiva não torna sua abordagem incompatível com a dimensão temporal. Ao contrário, a historicidade é componente fundamental à compreensão das representações sociais e é presença constante na teorização de seus autores. Mas não nos interessa um tempo que se traduz apenas em documentos arquivados a esperar perguntas adequadas, nem estados de consciência que existem espontaneamente, dissociados das atividades cotidianas dos seres humanos. Neste sentido, nossa intenção vai ao encontro de uma psicologia histórica que busca correlacionar processos sociais e mentais.

Não é uma jornada tranqüila, se levarmos em consideração as dificuldades de se trabalhar numa área de fronteira entre ciências, o que implica em desentendimentos e arestas de natureza epistemológica. Mas o momento é de ousadia e mesmo de transgressão e a palavra chave deste processo, àqueles que se dispõem a entender o que está acontecendo, é interpretação. As novas abordagens sugerem um contexto de renovação científica e de transformações profundas nas sociedades. A velocidade das transformações recobre muitas vezes as permanências, as ressignificações, as ausências e diferenças. A identidade brasileira nos remete a questões ainda hoje discutidas e mal resolvidas. Dos projetos das elites, que historicamente se debatem entre idéias importadas ou geradas nas entranhas de um ufanismo tropical, a cultura que se ergue das entranhas do cotidiano popular, alheio às teorias científicas, esse "quem somos nós" é não somente uma curiosidade intelectual mas fonte produtora de sentidos. Portanto, existem representações sociais do "ser brasileiro" que para serem compreendidas demandam análise histórica. Assim, nossas reflexões até aqui buscaram atingir uma dupla finalidade, por um lado, demonstrar que o estudo da representação social demanda história, por outro, defender a posição de que é possível analisar sob a ótica das representações sociais fatos históricos, como o ingresso de chineses no contexto de formação da nacionalidade brasileira.

\section{Referências}

Abric, J.-C. (1998). A abordagem estrutural das representações sociais. In A. S. P. Moreira \& D. C. Oliveira. (Orgs.), Estudos interdisciplinares de representação social (pp. 27-38). Goiânia: AB.

Alves-Mazzotti, A. J. (1996). O debate atual sobre os paradigmas de pesquisa em educação. Cadernos de Pesquisa, 96, 15-23.

Anais, 5. Jornada Internacional, 3. Conferência Brasileira sobre Representações Sociais. (2007). Brasília, DF: UnB. Recuperado em 03 janeiro 2008, de http://www.vjirs.com.br

Arruda, A. (2005). Pesquisa em representações sociais: A produção em 2003. In M. S. S. Menin \& A. M. Shimizu (Orgs.), Experiência e representação social: Questões teóricas e metodológicas (pp. 59-92). São Paulo: Casa do Psicólogo.

Bloch, M. (1976). Introdução à história. Lisboa: Europa-América.

Braudel, F. (1992). Escritos sobre a história (J. Guinsburg \& T. C. S. Mota, Trad.). São Paulo: Perspectiva. (Original publicado em 1969)

Burke, P. (1997). A escola dos Annales, 1929-1989: A revolução francesa da historiografia (N. Odalia, Trad.). São Paulo: EdUNESP.

Cardoso, C. F., \& Malerba, J. (Orgs.). (2000). Representações: Contribuição a um debate interdisciplinar. Campinas, SP: Papirus.

Castoriadis, C. (1982). A instituição imaginária da sociedade (G. Reynaud, Trad.). Rio de Janeiro: Paz e Terra. 
Chartier, R. (1990). A história cultural: Entre práticas e representações (M. M. Galhardo, Trad.). Rio de Janeiro: Bertrand.

Chartier, R. (1994). A história hoje: Dúvidas, desafios, propostas [Versão eletrônica]. Estudos Históricos, 7(13), 97-113. Recuperado em 03 janeiro 2008, de http://www.cpdoc.fgv.br/revista/arq/ 140.pdf

Diehl, A. A. (2002). Cultura historiográfica: Memória, identidade e representações. Bauru, SP: Edusc.

Domingues, J. M. (2003). Do ocidente à modernidade: Intelectuais e mudança social. Rio de Janeiro: Civilização Brasileira.

Elias, N. (1993). O processo civilizador: Vol. 2. Formação do estado e civilização (R. Jungmann, Trad.). Rio de Janeiro: Jorge Zahar. (Original publicado em 1939)

Farr, R. (1994). Representações sociais: A teoria e sua história. In P. Guareschi \& S. Jovchelovitch (Orgs.), Textos em representações sociais (2a ed., pp. 31-59). Petrópolis, RJ: Vozes.

Farr, R. (2004). As raízes da psicologia social moderna (P. A. Guareschi \& P. V. Maya, Trad., 6a ed.). Petrópolis, RJ: Vozes.

Freitas, M. S. (1998). Da micro-história a história das idéias. São Paulo: Cortez.

Ginzburg, C. (2007). Mitos, emblemas, sinais: Morfologia e história (F. Carotti, Trad.). São Paulo: Companhia das Letras. (Original publicado em 1986)

Heller, A. (2000). O cotidiano e a história (C. N. Coutinho \& L. Konder, Trad., 6a ed.). Rio de Janeiro: Paz e Terra. (Original publicado em 1970)

Jenkins, K. (2001). A história repensada (M. Vilela, Trad.). São Paulo: Contexto.

Jodelet, D. (2001). Representações sociais: Um domínio em expansão. In D. Jodelet (Org.), As representações sociais (L. Ulup, Trad., pp. 17-44). Rio de Janeiro: EdUERJ.
Jodelet, D. (2005). Loucuras e representações sociais (L. Magalhães, Trad.). Petrópolis, RJ: Vozes.

Jovchelovitch, S. (1994). Vivendo a vida com os outros: Intersubjetividade, espaço público e representações sociais. In P. Guareschi \& S. Jovchelovitch (Orgs.), Textos em representações sociais (2a ed., pp. 63-85). Petrópolis, RJ: Vozes.

Jovchelovitch, S. (2004). Psicologia social, saber, comunidade e cultura [Versão eletrônica]. Psicologia \& Sociedade, 16(2), 20-31. Recuperado em 06 janeiro 2008, de http://www.scielo.br/pdf/psoc/v16n2/ a04v16n2.pdf

Kuhn, T. S. (2006). A estrutura das revoluções científicas (B. V. Boeira \& N. Boeira, Trad., 9a ed.). São Paulo: Perspectiva. (Original publicado em 1962)

Le Goff, J. (2003). História e memória (B. Leitão, Trad., 5a ed.). São Paulo: EdUnicamp. (Original publicado em 1924)

Leme, M. A. V. S. (1995). O impacto da teoria das representações sociais. In M. J. Spink (Org.), $O$ conhecimento no cotidiano: As representações na perspectiva da psicologia social (pp. 46-57). São Paulo: Brasiliense.

Lincoln, Y. S., \& Guba, E. G. (2003). Controvérsias paradigmáticas, contradições e confluências emergentes. In N. K. Denzin \& Y. S. Lincoln (Orgs)., O planejamento da pesquisa qualitativa: Teorias e abordagens (S. R. Netz, Trad., pp. 169-192). Porto Alegre: Artmed.

Moscovici, S. (1978). A representação social da psicanálise (A. Cabral, Trad.). Rio de Janeiro: Zahar.

Moscovici, S. (2001). Das representações coletivas às representações sociais: Elementos para uma história. In D. Jodelet (Org.), As representações sociais (L. Ulup, Trad., pp. 45-66). Rio de Janeiro: EdUERJ.

Moscovici, S. (2003). Representações sociais: Investigações em psicologia social (P. Guareschi, Trad.). Petrópolis, RJ: Vozes. 
Moscovici, S. (2007). Un largo prefácio. In A. Arruda \& M. Alba (Orgs.), Espacios imaginarios y representaciones sociales (pp. 7-13). Barcelona: Anthropos.

Pesavento, S. J. (1995). Em busca de uma outra história: Imaginando o imaginário. Revista Brasileira de História, 15(29), 9-27.

Reis, J. C. (2005). História e teoria: Historicismo, modernidade, temporalidade e verdade. Rio de Janeiro: EdFGV.

Ribeiro, K. C. S., Oliveira, J. S. C., Coutinho, M. P. L., \& Araújo, L. F. (2007). Representações sociais da depressão no contexto escolar [Versão eletrônica]. Paidéia (Ribeirão Preto), 17, 417-430. Recuperado em 18 novembro 2008, de http:// www.scielo.br/pdf/paideia/v17n38/v17n38a11.pdf

Rouquette, M.-L. (1994). Sur la connaissance des masses: Essai de psychologie politique. Grenoble: Presses Universitaires de Grenoble.

Said, E. W. (2007). Orientalismo: O oriente como invenção do ocidente (R. Eichenberg, Trad.). São Paulo: Companhia das Letras. (Original publicado em 1978)

Schaff, A. (1987). História e verdade (M. P. Duarte, Trad., 4a ed.). São Paulo: Martins Fontes. (Original publicado em 1971)

Spink, M. J. (1994). Desvendando as teorias implícitas: Uma metodologia de análise das representações sociais. In P. Guareschi \& S. Jovchelovitch (Orgs.), Textos em representações sociais (2a ed, pp. 117145). Petrópolis, RJ: Vozes.

Spink, M. J., \& Menegon, V. M. (2000). A pesquisa como prática discursiva: Superando os horrores metodológicos. In M. J. Spink (Org.), Práticas discursivas e produção de sentidos no cotidiano: Aproximações teóricas e metodológicas (2a ed., pp. 63-122). São Paulo: Cortez.

Vala, J. (1993). As representações sociais no quadro dos paradigmas e metáforas da psicologia social. Análise Social, 28, 123-124.
Wagner, W. (1998). Sócio-gênese e características das representações sociais. In A. S. P. Moreira \& D. C. Oliveira. (Orgs.), Estudos interdisciplinares de representação social (pp. 3-26). Goiânia: AB.

Artigo recebido em 13/05/2008.

Aceito para publicação em 20/11/2008.

Endereço para correspondência:

João Gilberto da Silva Carvalho. Rua Alberto Maier, 180. CEP 28970-000. Araruama-RJ, Brasil. E-mail: wuwei@ig.com.br

João Gilberto da Silva Carvalho é doutorando do Programa de Pós-graduação em Psicologia da Universidade Federal do Rio de Janeiro, bolsista CAPES.

Angela Arruda é Professora Adjunta do Instituto de Psicologia da Universidade Federal do Rio de Janeiro. 